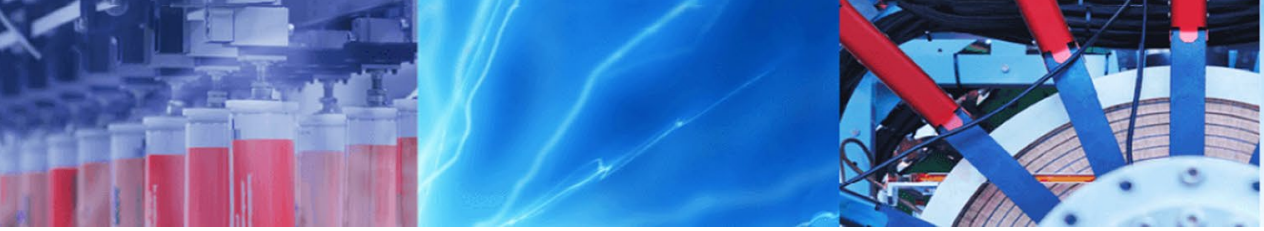

Research Article

\title{
Effect of particle size and sintering time on the mechanical properties of porous Ti-6Al-4V implant
}

\author{
Akeem A. Azeez ${ }^{1,2}$ (D) Yiporo Danyuo ${ }^{3}$ John. D. Obayemi ${ }^{4}$
}

Received: 25 January 2020 / Accepted: 30 March 2020 / Published online: 5 April 2020

(c) Springer Nature Switzerland AG 2020

\begin{abstract}
Titanium alloys have been extensively used in biomedical applications owing to its low density, excellent biocompatibility (i.e., biological and chemical inertness), and unique mechanical properties. However, there is a high disparity between Young's moduli of the implant and the natural bone. This disparity causes stress shielding in the body. This paper presents the effect of particle size and sintering time of Ti-6Al-4V powder used in the formation of a porous implant, sintered at $980^{\circ} \mathrm{C}$. Morphological characteristics of the sintered samples were obtained with a scanning electron microscope. The effect of surface hydrophilicity of the samples was elucidated via surface wettability testing using contact angle measurement with bio-fluid. Mechanical characterization was also evaluated with nanoindentation and a universal testing machine. The relation between Young's modulus and sintering time was presented. It was observed that the wettability decreases with sintering time and the Ti alloy powder with particle size $<150 \mu \mathrm{m}$ had the Young's modulus that is closer to the modulus of the bone; the optimum sintering time was $5 \mathrm{~h}$.
\end{abstract}

Keywords Porous Ti-6Al-4V implant · Surface wettability · Young's modulus · Sintering time $\cdot$ And particle size effect

\section{Introduction}

Metal plates have been used as implants to fix or replace lost organs as well as organs with unsatisfied functions [1]. Lane first introduced this method in 1890, where metal plates were used for bone fracture fixation [2]. There were issues of low yield strength and poor corrosion resistance facing metal implants in the past until several research works [3-6] that were carried out in the 1920s that led to the disco very of 18-8 stainless steel for potential applications [7-9]. The most widely used alloy for biomedical implant in recent times is $316 \mathrm{~L}$ stainless steel (316L SS) due to its low cost as well as its ability to provide reasonable corrosion resistant [2]. However, when there is a need for high wear resistance material for applications such as artificial joints, the CoCrMo alloys, and titanium alloys are usually considered [2]. Titanium and Ti-6Al-4V are much used in orthopedics because of their high shear strength and wear resistance [9].

For the past decades, the world has witnessed a surge in the number of road accidents [10], therefore, there is a high demand for metallic bone plates for bone fractures [10]. However, with more youths coming down with need for bone implant due to accidents and the average service life of an implant is between 10 and 15 years, so there is high probability that orthopedic surgical patients will need revision surgeries in their lifetime. Hence, Ti-alloys with porous structure could be studied to provide solutions to fixation of bone fractures associated with the high rates of accidents.

The short service life of implants is associated with micro-shifts at the interface between the implant and

$\triangle$ Akeem A. Azeez, azeeza2@myumanitoba.ca|'Biomedical Engineering Program, University of Manitoba, Manitoba, Canada. ${ }^{2}$ Department of Materials Science and Engineering, African University of Science and Technology, Abuja, Nigeria. ${ }^{3}$ Departments of Mechanical Engineering, Ashesi University, Berekuso, Ghana. ${ }^{4}$ Department of Mechanical Engineering, Worcester Polytechnic Institute, 100 Institute Rd, Worcester, MA 01609, USA. 
the bone due to the discrepancy between the two mechanical moduli [11]. There is a dissimilarity between Young's modulus of titanium implant (103-120 GPa) and bone $(10-30 \mathrm{GPa})$ which can result into stress shielding that can affect the healing and remodeling of the bone [12]. There is a direct relationship between Young's modulus and other mechanical properties of Ti-6Al-4V, therefore, a reduction in the elastic modulus of the alloy will also lead to decrease in its strength; once the strength is enhanced, the elastic modulus also increases [12]. So, there is a need to strike a balance between the elastic modulus and the strength of the Ti- $6 \mathrm{Al}-4 \mathrm{~V}$ orthopedic implant.

In this article, the mechanical properties of porous $\mathrm{Ti}-6 \mathrm{Al}-4 \mathrm{~V}$ was evaluated by varying the sintering time and particle sizes of porous Ti-alloy powder while the hydrophilicity of the samples were examined by contact angle measurement.

\section{Materials and methods}

\subsection{Materials}

Spherical Ti-6Al-4V alloy powder was procured from Phelly Material Inc. (New Jersey, USA), alumina ceramic crucibles were purchased from Sigma Aldrich Co. (St. Louis, MO, USA), whiles British Standard (BS) sieve, muffle furnace were both obtained from ELE International (Model no: 88-0110/02, England, UK). A setup for contact angle/ wettability studies comprised of a black box, 60 Watts incandescent bulb, a converging lens, a digital camera, phosphate-buffered saline solution (disodium hydrogen phosphate $(1.44 \mathrm{~g} / \mathrm{L})$, potassium chloride $(0.2 \mathrm{~g} / \mathrm{L})$, potassium dihydrogen phosphate $(0.24 \mathrm{~g} / \mathrm{L})$ and sodium chloride $(8.0 \mathrm{~g} / \mathrm{L}))$ with $\mathrm{pH}$ of 7.00 as bio-fluid and micropipettes were locally purchased in Abuja, Nigeria.

\section{Experimental procedures}

\subsection{Sintering process}

The as-received Ti-6Al-4V powder was sieved into three different particle sizes ranging from $0-150 \mu \mathrm{m}$ and 151-300 $\mu \mathrm{m}$ using the BS sieves. The different particle sizes were then placed in alumina ceramic crucibles and heated in a muffle furnace to $980^{\circ} \mathrm{C}$ at a ramp rate of $20^{\circ} \mathrm{C} / \mathrm{min}$ and were held at this temperature for $3 \mathrm{~h}, 4 \mathrm{~h}$ and $5 \mathrm{~h}$. The furnace was then allowed to cool down with the samples in it at the ramp rate of $20^{\circ} \mathrm{C} / \mathrm{min}$.

\subsection{Sample preparation for optical and SEM characterizations}

The sintered samples were first sprayed with ethanol, then compressed air was used on each sample to remove unattached Ti-6Al-4V particles from their surfaces. No other metallographic procedures were carried out on the sintered samples before the optical and SEM examinations.

\subsection{Contact angle measurement}

The contact angles, $\theta_{e}$ were used to determine the wettability of the sintered Ti- $6 \mathrm{Al}-4 \mathrm{~V}$ samples. This measurement was developed by Young in 1805 [13] by establishing the angle that a liquid drop will make with a solid surface. The contact angle is defined by the mechanical equilibrium of the drop under the influence of three interfacial tensions which includes the solid-vapor $\left(\gamma_{s v}\right)$, solid-liquid $\left(\gamma_{s l}\right)$ and liquid-vapour $\left(\gamma_{/ v}\right)$ surface tensions. The equilibrium equation is known as Young's equation [14]:

$\gamma_{\mid V} \cos \theta_{e}=\gamma_{s V}-\gamma_{s l}$

where $\theta_{e}$ is known as Young contact angle.

The contact angle measurement was obtained from a direct photograph, through the deflection (or reflection) of light rays by the liquid prism. The surface of each sample was cleaned with ethanol and compressed air to get rid of any loose Ti-6Al-4V particles. The sample was then carefully placed on the sample holder in a carton box, while the bulb was switched on. The micropipette was used to draw $50 \mu \mathrm{L}$ of the prepared solution, and few drops of the buffer solution were gently dropped on the substrates through the provided opening on the box. The biofluid stayed for $2 \mathrm{~s}$ on each sample before the digital images were recorded. The recorded images were subsequently transferred to Gwyddion 2.45 software package to determine the contact angles between the liquid drop and the sample.

\subsection{Determination of Young's modulus}

The Young's moduli of the samples were characterized using nanoindentation techniques [7]. This method was chosen because of its non-destructive nature compared to other mechanical testing methods. Elastic modulus, $\mathrm{E}$, and hardness, $\mathrm{H}$, were the mechanical properties frequently measured using load and depth sensing indentation techniques. The data were extracted from one complete cycle of loading and unloading [15]. The deformation during loading is assumed to be both elastic and plastic as the indenter formed permanent impressions 
on the samples. During unloading, elastic displacement was expected to be recovered and that aid in analysis. This method is therefore not applicable to materials in which plasticity reverses during unloading. The Young's modulus of the specimen was extracted using Eqs. (2) and (3), respectively.

$S=\frac{2}{\sqrt{\pi}} E_{r} \sqrt{A}$

$\frac{1}{E_{r}}=\frac{\left(1-v^{2}\right)}{E}+\frac{\left(1-v_{i}^{2}\right)}{E_{i}}$

where $S$ is the measured unloading stiffness and $A$ is the contact area, $E_{r}$ is known as the reduced modulus, which takes into account the effect of non-rigidity of the indenters. $E$ and $v$ are Young's modulus and Poisson's ratio for the specimen, respectively. $E_{i}$ and $v_{i}$ are the same parameters for the indenter.

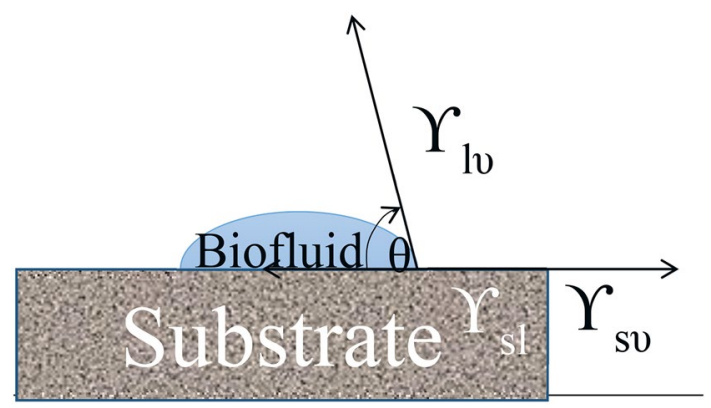

Fig. 1 Contact angle parameters (Modified after [13])

\subsection{Compressive strength measurement}

Since the application of the implant in the body will be subjected to compressive stresses, the compressive strength of the samples was obtained. The compressive strength of each sample was determined using a universal testing machine. Each sample has a hemisphere shapelike, and the load rate was $3000 \mathrm{~mm} / \mathrm{min}$ (Fig. 1).

\section{Results and discussion}

\subsection{Optical and SEM characterizations}

The optical results from ProScope ${ }^{\circledR}$ optical instrument are presented in Fig. 2; it was observed that as the sintering time increases, the pores between the Ti-6Al-4V powder particles disappeared gradually, this is more evident if you compare Fig. 2a and b. More detailed images are shown in Fig. 3 below using SEM micrographs. The micrographs in Fig. 3 are for same particle size range (300-212 $\mu \mathrm{m}$ ) sintered at different temperatures; the contrast between the void's sizes in Fig. $3 \mathrm{~b}$ and f illustrates the elaborate effect of sintering time on pores within the samples.

\subsection{Contact angles and wettability}

The effect of particles size and sintering time on the contact angle, which signifies the wettability of the substrate are presented in Fig. 4. The wettability for particles sizes 212-300 $\mu \mathrm{m}$ was much improved with their contact angles less $25^{\circ}$. This angle was also less than the contact angles for $<150 \mu \mathrm{m}$, and $212-300 \mu \mathrm{m}$. For particles sizes 212-300 $\mu \mathrm{m}$, the contact angles, $\theta$ at $3 \mathrm{~h}, 4 \mathrm{~h}$ and $5 \mathrm{~h}$ (a)

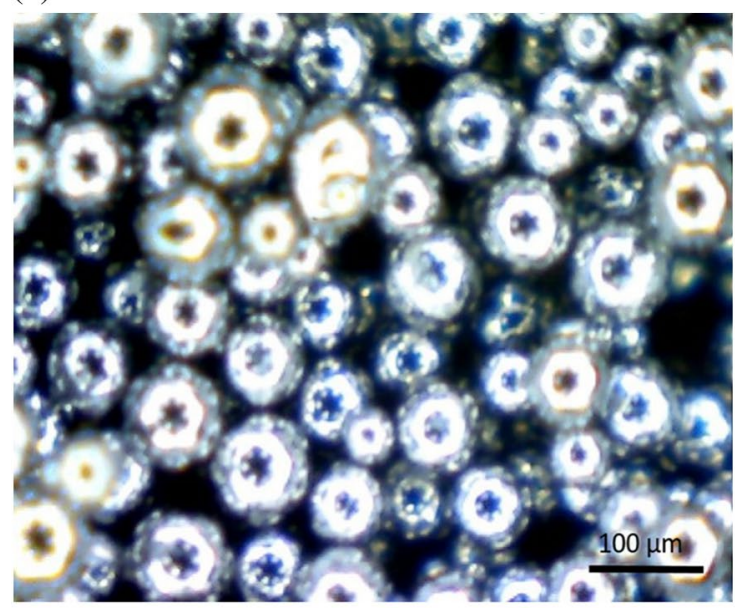

(b)

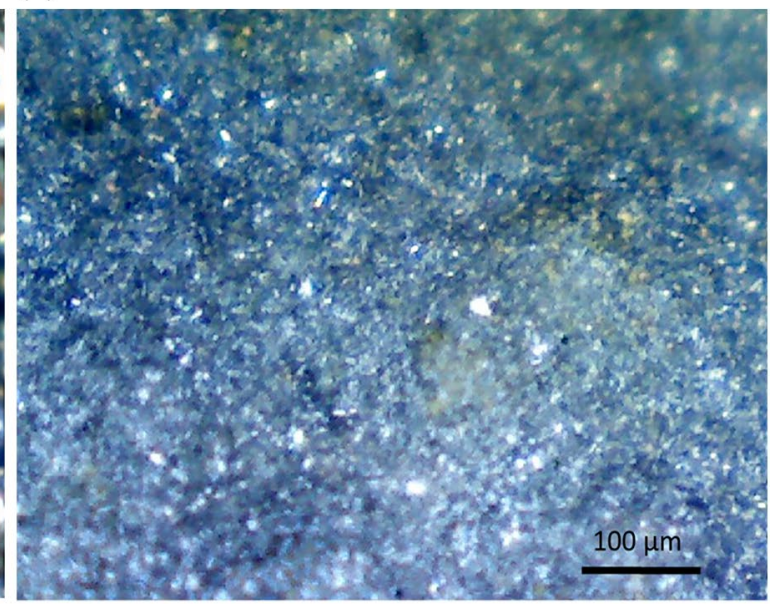

Fig. 2 a Optical image of As-received Ti-6Al-4V powder. b Optical image of Ti-6Al-4V with particle size 212-150 $\mu \mathrm{m}$, sintered for $4 \mathrm{~h}$ 
(a)

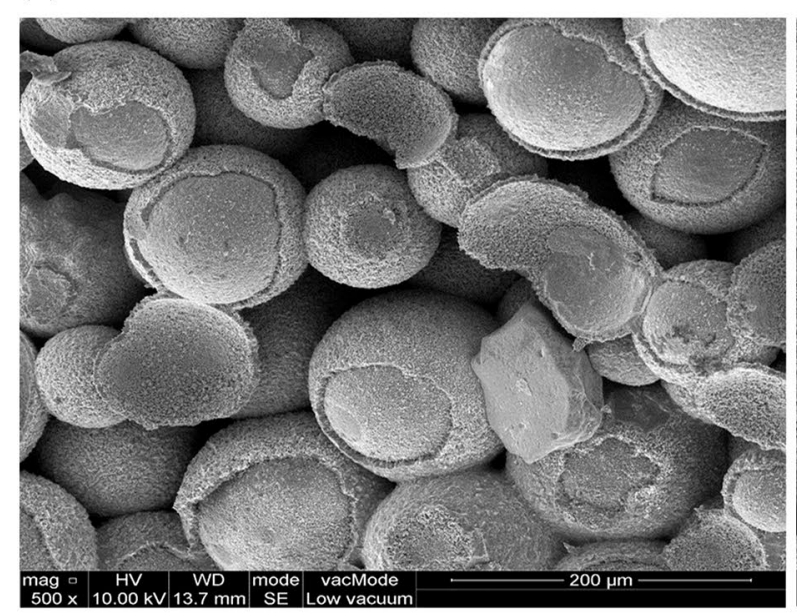

(c)

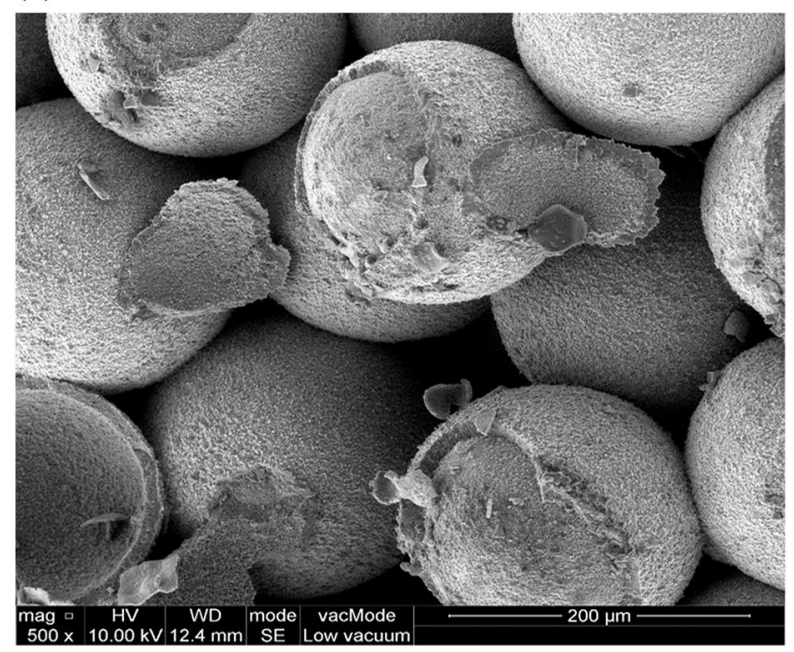

(e)

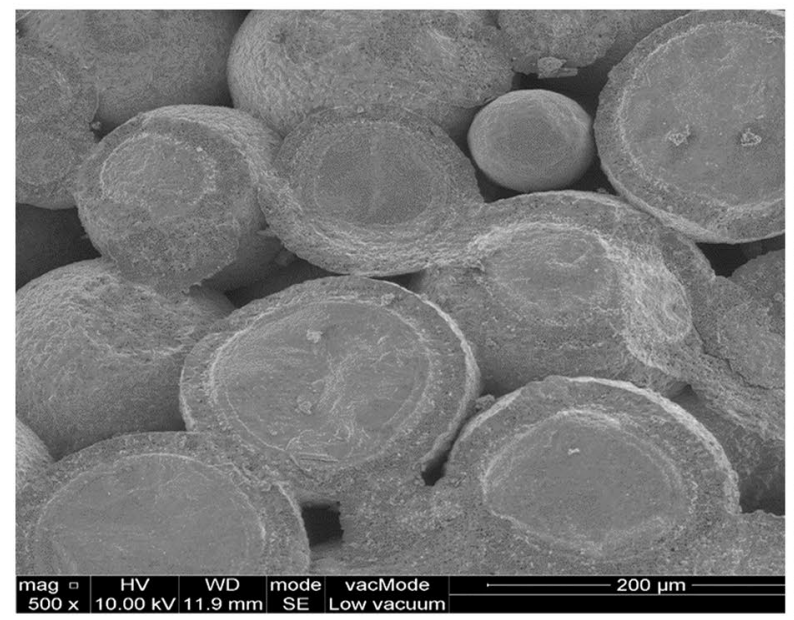

(b)

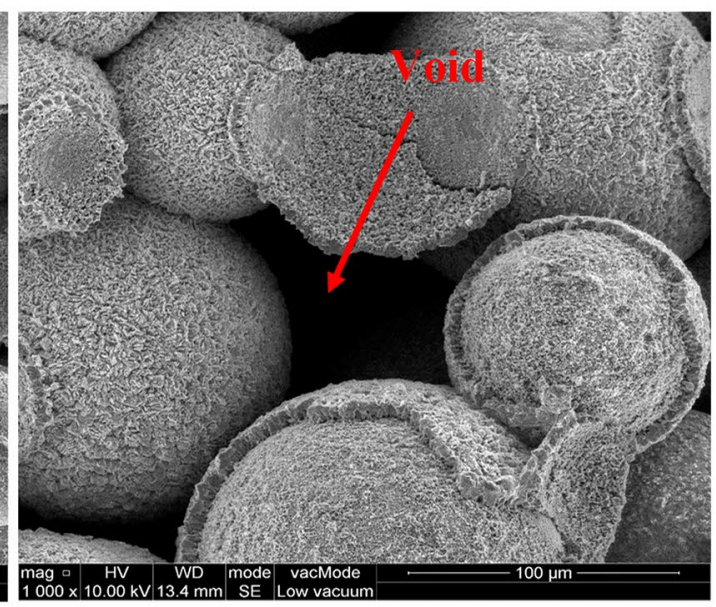

(d)

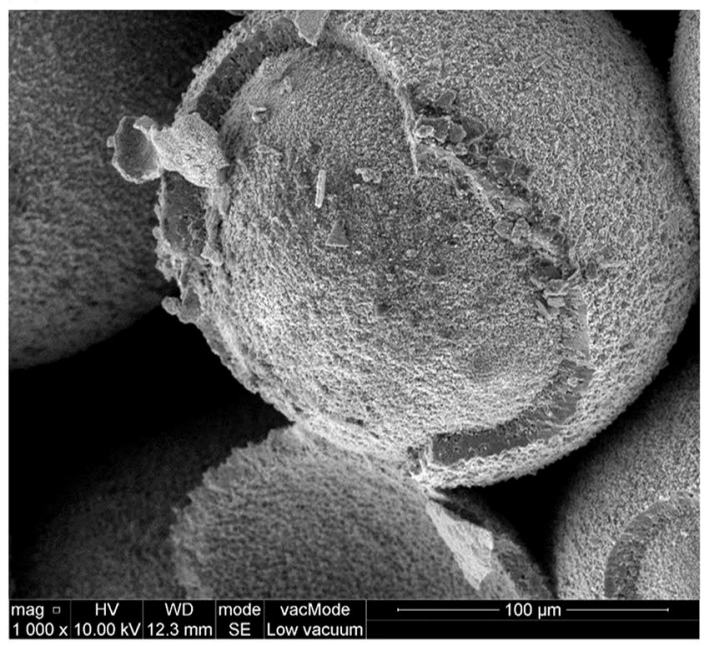

(f)

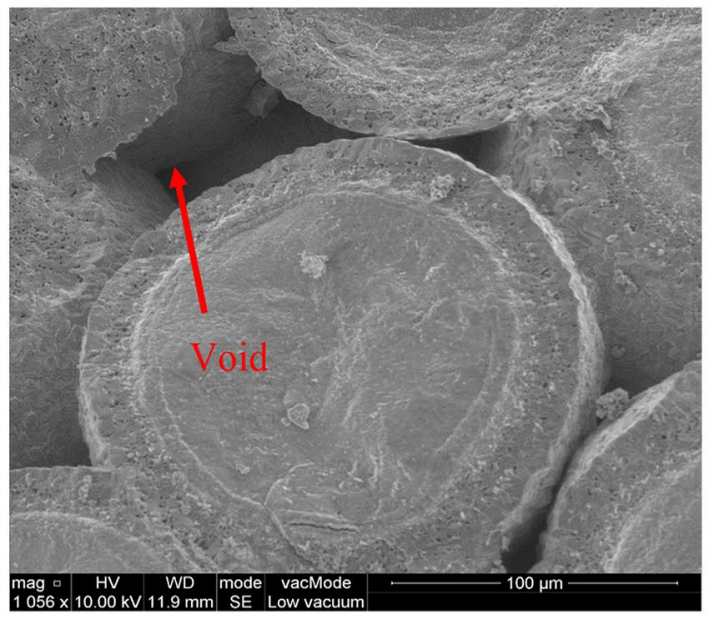

Fig. 3 SEM micrographs of Ti-6Al-4V with particle size: a $300-$ $212 \mu \mathrm{m}$ sintered for $3 \mathrm{~h}(\times 500)$, b $300-212 \mu \mathrm{m}$ sintered for $3 \mathrm{~h}$ $(\times 1000)$ c 300-212 $\mu \mathrm{m}$ sintered for $4 \mathrm{~h}(\times 500)$, d 300-212 $\mu \mathrm{m}$ sin- tered for $4 \mathrm{~h}(\times 1000)$. e 300-212 $\mu \mathrm{m}$ sintered for $5 \mathrm{~h}(\times 500)$. f 300$212 \mu \mathrm{m}$ sintered for $5 \mathrm{~h}(\times 1056)$ 


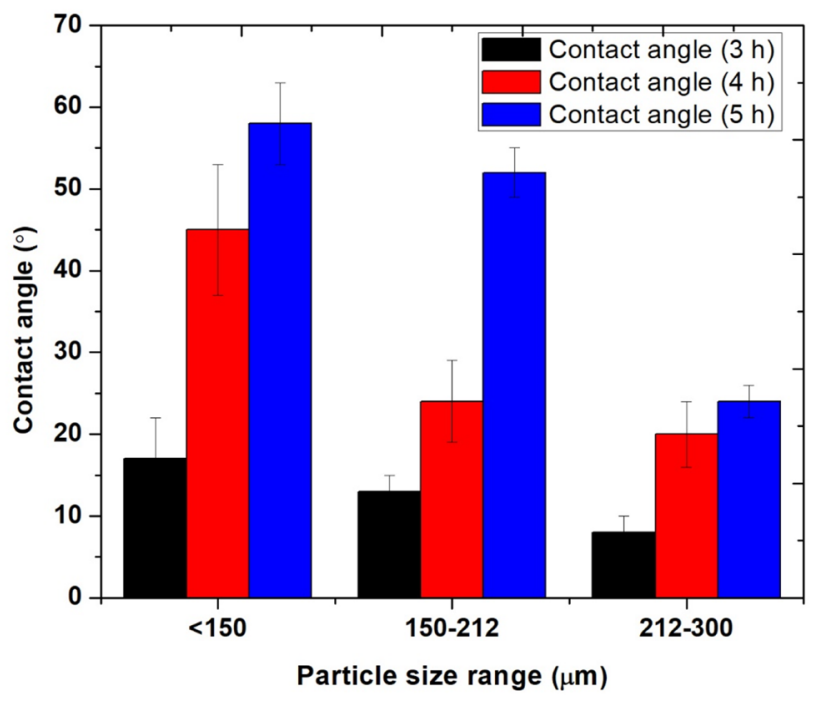

Fig. 4 Wettability via contact angle versus particle sizes

are respectively $\sim 7^{\circ}, \sim 20^{\circ}$, and $25^{\circ}$. For particles sizes $150-212 \mu \mathrm{m}$, the contact angles, $\theta$ at $3 \mathrm{~h}, 4 \mathrm{~h}$ and $5 \mathrm{~h}$ are $\sim 15^{\circ}, \sim 25^{\circ}$ and $52^{\circ}$, respectively whiles $\theta$ for $<150 \mu \mathrm{m}$ at $3 \mathrm{~h}, 4 \mathrm{~h}$, and $5 \mathrm{~h}$ were $\sim 18^{\circ}, \sim 45^{\circ}$, and $57^{\circ}$, respectively.

However, it is evident that the largest particle size group $(212-300 \mu \mathrm{m})$ has the lowest contact angles which means that it has the highest wettability compared to particles sizes $<150 \mu \mathrm{m}$ and $150-212 \mu \mathrm{m}$. This observation is because coarse particles sinter slower than finer particles thereby creating micro-roughness, and besides, the biofluid stayed on the samples for $2 \mathrm{~s}$ which allowed the biofluid to fill the pores of the samples through capillary action. There is an apparent effect of sintering time and particles size on the contact angles. From our view, sintering time of $3 \mathrm{~h}$ has better wettability for the formation of porous Ti-6AI-4V samples because as the sintering time increases, the titanium alloy particles are more likely to become denser. Lower contact angles suggest the force of adhesion between the solid-liquid interface was more significant than the cohesive force of the liquid-liquid interaction.

\section{Mechanical properties}

A diamond Berkovich indenter was used for the analysis; the elastic modulus and the Poisson ratio of the indenter were $1141 \mathrm{GPa}$ and 0.07 , respectively [16]. The Young's moduli for the samples with different particle size ranges are presented in Fig. 5.

The Young's moduli of the samples increase with the sintering time due to an increase in packing density of the particles, which gradually eliminate the pores within

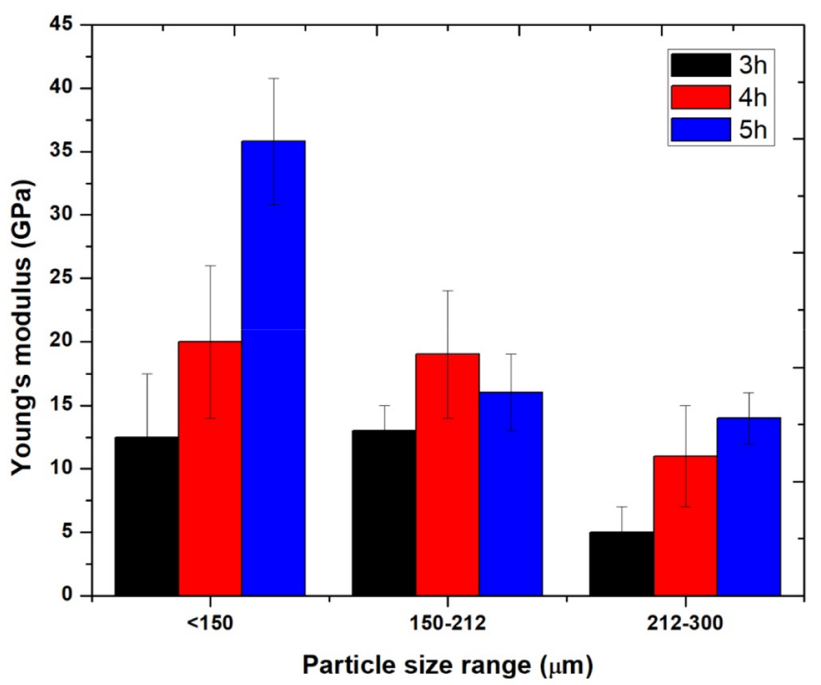

Fig. 5 Effect of sintering time on Young's modulus for different particle sizes

the samples. This led to stiffer and denser material with relatively high Young's modulus. This result coincides with what was reported by some researchers. Lucía Reig et al. observed that the stiffness and bending strength of sintered porous Ti-6Al-4V samples increases with sintering time $[17,18]$, while Jose Luis et al. established that there is a polynomial relationship between Young's modulus and relative density of the sintered porous Ti alloy [19]. The negative effect of porosity on Young's modulus was also corroborated by Martínez et al. [20].

In contrast, the above assertion was only true for samples with particle sizes $<150 \mu \mathrm{m}$ and $212-300 \mu \mathrm{m}$. The Young's modulus result from samples with particle size 150-212 $\mu \mathrm{m}$ was not consistence with what was reported in literatures even after repeated trials.

However, samples sintered from finer particle sizes tend to have higher Young's modulus when compared to ones formed from coarse particle sizes, one of the reasons for this observation is that finer particles are likely to develop better interparticle necking during sintering which in turn will reduce the porosity and give rise to higher Young's modulus. This is also in line with was reported various literatures $[18,19]$.

The Young's modulus of samples with particles less than $150 \mu \mathrm{m}$ sintered for $5 \mathrm{~h}$ was found to be $\sim 35 \mathrm{GPa}$, and this is much closer to that of the natural bone.

\subsection{Compressive strength}

The compressive strength was extracted from the stress versus deformation graph using the data from the universal testing machine. The compressive strength indicates a 


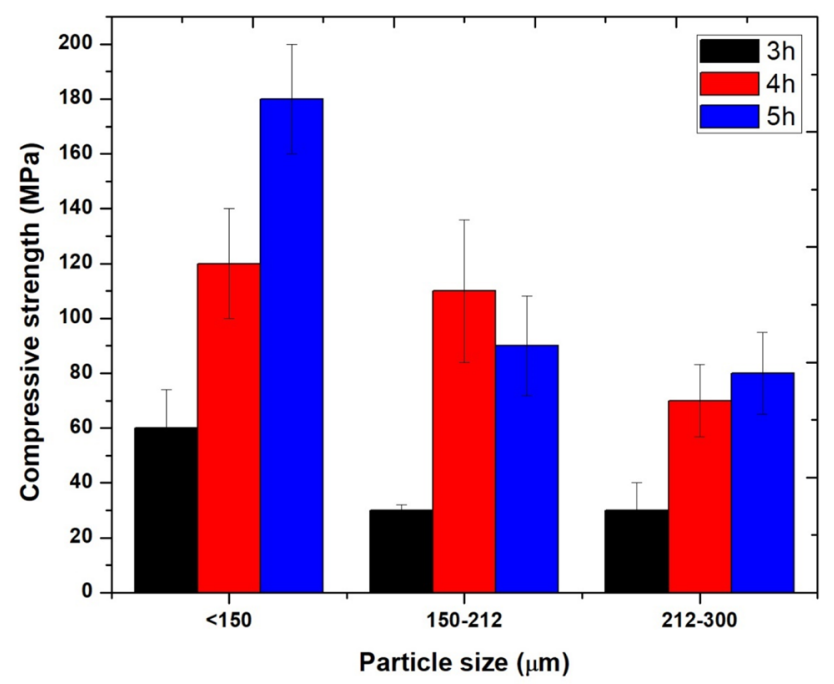

Fig. 6 Effect of sintering time on Compressive strength for different particle sizes

point on the graph where the applied stress is no longer proportional to deformation; this is also known as the yield point. Figure 6 shows the compressive strengths obtained for different particle sizes and at different durations.

The sample with sizes less than $150 \mu \mathrm{m}$ sintered for $5 \mathrm{~h}$ has the highest compressive strength of $180 \mathrm{MPa}$; one of the reasons for this observation is that the less than $150 \mu \mathrm{m}$ sample has the highest particle size variation thereby making it easy for smaller particles to diffuse into the pores in the sample during sintering.

\section{Conclusion}

This work presents the effect of sintering time on the mechanical properties of Ti-6Al-4V powder. The wettability of the Ti alloy samples was also evaluated. It was observed that the wettability decreases with an increase in sintering time. The smallest particle size group $(<150 \mu \mathrm{m})$ gives the highest contact angle while the particle sizes 212-300 $\mu \mathrm{m}$ has the lowest contact angle indicating highly wettable surface due to micro-roughness which enhances the spread of the bio-fluid drop.

Furthermore, $3 \mathrm{~h}$ sintering time has the lowest contact angle compared to other sintering time, and this suggests that $3 \mathrm{~h}$ sintering time would be optimum for the formation of porous Ti- $6 \mathrm{Al}-4 \mathrm{~V}$ but unfortunately, the samples sintered at this temperature do not have the mechanical capability to function properly in a load bearing area of the body.

In addition, Young's modulus and compressive strength of the samples through Nano-indentation and universal testing machine were analyzed, respectively. It was found that the particles size range of $<150 \mu \mathrm{m}$ sintered for $5 \mathrm{~h}$ has Young's modulus of $\sim 35 \mathrm{GPa}$ which is most closer to that of the bone (bone Young's modulus is between 10-30 $\mathrm{GPa}$ ); when compared with Ti-6Al-4V datasheet (103-120 $\mathrm{GPa}$ ), we observed that there is great disparity between the two moduli. One of the reasons for the large difference in the values of Young's moduli is the presence of voids due to the sintering process of the samples, the voids make dislocation of the Ti alloy atoms easier, thereby resulting in the smaller Young's modulus for the porous Ti alloy. Metallic powder sintered at lower temperatures tends to have lot of voids or porosity which reduces the mechanical properties and increases the wettability of the samples.

More relevant analysis should be carried out to determine how the particle sizes and the different sintering time of the samples may affect cell proliferation and focal adhesion of the osteoblast cells; to measure the effect of porosity on the mechanical properties of the samples. These are challenges for future work.

Acknowledgements The authors are very grateful to Petroleum Technology Development Fund (PTDF), The Pan African Materials Institute (PAMI) and The African University of Science and Technology, Abuja, for sponsoring this research.

\section{Compliance with ethical standards}

Conflict of interest The authors declare no conflict of interests.

\section{References}

1. Mhaede M, Ahmed A, Wollmann M, Wagner L (2015) Evaluating the effects of hydroxyapatite coating on the corrosion behavior of severely deformed 316Ti SS for surgical implants. Mater Sci Eng C 50:24-30. https://doi.org/10.1016/j.msec.2015.01.093

2. Hermawan H, Ramdan D, Djuansjah JRP (2011) Metals for biomedical applications biomedical engineering: from theory to applications, Reza Fazel-Rezai. IntechOpen. https://doi. org/10.5772/19033

3. Antunes RA, De Oliveira MCL (2012) Corrosion fatigue of biomedical metallic alloys: mechanisms and mitigation. Acta Biomater 8(3):937-962. https://doi.org/10.1016/j.actbi 0.2011 .09 .012

4. Su Y et al (2018) Bioinspired surface functionalization of metallic biomaterials. J Mech Behav Biomed Mater 77:90-105. https:// doi.org/10.1016/j.jmbbm.2017.08.035

5. Ibrahim MZ, Sarhan AAD, Yusuf F, Hamdi M (2017) Biomedical materials and techniques to improve the tribological, mechanical and biomedical properties of orthopedic implants: a review article. J Alloys Compd 714:636-667. https://doi.org/10.1016/j. jallcom.2017.04.231

6. Harun WSW et al (2018) A comprehensive re view of hydroxyapatite-based coatings adhesion on metallic biomaterials. Ceram Int 44(2):1250-1268. https://doi.org/10.1016/j.ceram int.2017.10.162

7. Williams RL, Brown SA, Merritt K (1988) Electrochemical studies on the influence of proteins on the corrosion of implant 
alloys. Biomaterials 9(2):181-186. https://doi.org/10.1016/01429612(88)90119-6

8. Revie RW, Greene ND (1969) Comparison of the in vivo and in vitro corrosion of 18-8 stainless steel and titanium. J Biomed Mater Res 3(3):465-470. https://doi.org/10.1002/jbm.820030308

9. Li JP, Li SH, Van Blitterswijk CA, De Groot K (2005) A novel porous Ti6A14V: characterization and cell attachment. J Biomed Mater Res A 73(2):223-233. https://doi.org/10.1002/jbm.a.30278

10. Nantulya VM, Reich MR (2003) Equity dimensions of road traffic injuries in low- and middle-income countries. Inj Control Saf Promot 10(1-2):13-20. https://doi.org/10.1076/icsp.10.1.13.14116

11. Chen J, Paetzell E, Zhou J, Lyons L, Soboyejo W (2010) Osteoblast-like cell ingrowth, adhesion and proliferation on porous Ti-6Al-4V with particulate and fiber scaffolds. Mater Sci Eng C 30(5):647-656. https://doi.org/10.1016/j.msec.2010.01.005

12. Meyers MA, Mishra A, Benson DJ (2006) Mechanical properties of nanocrystalline materials. Prog Mater Sci 51(4):427-556. https ://doi.org/10.1016/j.pmatsci.2005.08.003

13. Lamour $\mathrm{G}$ et al (2010) Contact angle measurements using a simplified experimental setup. J Chem Educ 87(12):1403-1407. https://doi.org/10.1021/ed100468u

14. Choi WY, Park HJ, Ahn DJ, Lee J, Lee CY (2002) Wettability of chitosan coating solution on 'Fuji' apple skin. J Food Sci 67(7):26682672. https://doi.org/10.1111/j.1365-2621.2002.tb08796.x

15. Doerner MF et al (1986) Plastic properties of thin films on substrates as measured by submicron indentation hardness and substrate curvature techniques. J Mater Res 1(06):845-851. https://doi.org/10.1557/JMR.1986.0845
16. Shuman DJ, Costa ALM, Andrade MS (2007) Calculating the elastic modulus from nanoindentation and microindentation reload curves. Mater. Charact. 58(4):380-389. https://doi.org/10.1016/j. matchar.2006.06.005

17. Reig L, Amigó, Busquets DJ, Calero JA (2012) Development of porous Ti6Al4V samples by microsphere sintering. J Mater Process Technol 212(1):3-7. https://doi.org/10.1016/j.jmatprotec .2011.06.026

18. Reig L, Tojal C, Busquets DJ, Amigo V (2013) Microstructure and mechanical behavior of porous $\mathrm{Ti}-6 \mathrm{Al}-4 \mathrm{~V}$ processed by spherical powder sintering. Materials (Basel, Switzerland) 6(10):48684878. https://doi.org/10.3390/ma6104868

19. Cabezas-Villa JL, Lemus-Ruiz J, Bouvard D, Jiménez O, VergaraHernández HJ, Olmos L (2018) Sintering study of Ti6Al4V powders with different particle sizes and their mechanical properties. Int J Miner Metall Mater 25(12):1389-1401. https://doi. org/10.1007/s12613-018-1693-5

20. Martínez C et al (2020) Effect of porosity on mechanical and electrochemical properties of Ti-6Al-4V alloy. Electrochim Acta 338:135858. https://doi.org/10.1016/j.electacta.2020.135858

Publisher's Note Springer Nature remains neutral with regard to jurisdictional claims in published maps and institutional affiliations. 